\title{
Intraoperative Conebeam CT for Assessment of Intracochlear Positioning of Electrode Arrays in Adult Recipients of Cochlear Implants
}

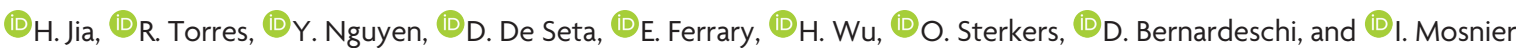

\begin{abstract}
BACKGROUND AND PURPOSE: Intraoperative conebeam CT has been introduced into the operating room and provides quick radiologic feedback. This study aimed to investigate its utility in the assessment of the positioning of the electrode array after cochlear implantation.
\end{abstract}

MATERIALS AND METHODS: This was a retrospective study of 51 patients ( 65 ears) with intraoperative imaging by conebeam CT (O-arm) after cochlear implantation between 2013 and 2017. Correct placement into the cochlea was immediately identified. Positioning assessments were later analyzed with OsiriX software.

RESULTS: Intraoperative imaging was quickly performed in all cases. No misplacement into the vestibule or semicircular canals was found. A foldover of the implanted array was identified in 1 patient. Secondary analysis by 2 raters showed excellent agreement on insertion depth angle (intraclass correlation $=0.96, P<.001$ ) and length of insertion of the electrode array (intraclass correlation coefficient $=0.93, P=$ .04) measurements. The evaluation of the number of extracochlear electrodes was identical between the 2 raters in $78 \%$ of cases (Cohen $\kappa=0.55, P<.001)$. The scalar position was inconsistent between raters. When we compared $\mathrm{O}$-arm and high-resolution CT images in 14 cases, the agreement was excellent for insertion depth angle (intraclass correlation coefficient $=0.97, P<.001$ ) and insertion length (intraclass correlation coefficient $=0.98, P<.001$ ), good for the number of extracochlear electrodes (Cohen $\kappa=0.63, P=.01$ ), but moderate for the scalar position (Cohen $\kappa=0.59, P=.02$ ).

CONCLUSIONS: Intraoperative conebeam CT using the O-arm is a safe, rapid, easy, and reliable procedure to immediately identify a misplacement or foldover of an electrode array. The insertion depth angle, insertion length, and number of electrodes inserted can be accurately assessed.

ABBREVIATIONS: $\mathrm{CBCT}=$ conebeam $\mathrm{CT} ; \mathrm{HRCT}=$ high-resolution $\mathrm{CT} ; \mathrm{ICC}=$ intraclass correlation coefficient

T he cochlear implant is an electronic medical device for rehabilitation of profound hearing loss. When implanted into the cochlea, the electrode array stimulates the spiral ganglion cells

Received September 14, 2017; accepted after revision December 28.

From the Unité de Réhabilitation Chirurgicale Mini-Invasive Robotisée de l'Audition (H.J., R.T., Y.N., D.D.S., E.F., O.S., D.B., I.M.), Sorbonne Universités, Université Pierre et Marie Curie Paris 6, Institut National de la Santé et de la Recherche Médicale, Paris, France; Otologie, Implants Auditifs et Chirurgie de la Base du Crane (H.J., Y.N., D.D.S., E.F., O.S., D.B., I.M.), Paris Assistance Publique, GHU PitiéSalpêtrière, Service ORL, Paris, France; Department of Otolaryngology-Head and Neck Surgery (H.J., H.W.), Shanghai Ninth People's Hospital, Shanghai Jiaotong University School of Medicine, Shanghai, China; and Shanghai Key Laboratory of Translational Medicine on Ear and Nose Diseases (H.J.), Jiaotong University School of Medicine, Shanghai, China.

Paper previously presented, in part, as preliminary results at: International Conference on Cochlear Implants and Other Implantable Technologies, May 11-14, 2016; Toronto, Ontario, Canada.

Please address correspondence to Isabelle Mosnier, MD, Unité Otologie, Implants Auditifs et Chirurgie de la Base du Crâne, GH Pitié-Salpêtrière-Bâtiment Castaigne, 47-83 Boulevard de l'Hôpital, 75651 Paris Cedex 13, France; e-mail: isabelle.mosnier@aphp.fr

http://dx.doi.org/10.3174/ajnr.A5567 with encoded electrical impulses; therefore, correct placement of the array is essential for a well-functioning cochlear implant. Imaging examination after implantation with, for example, radiography and fluoroscopy or high-resolution CT (HRCT) is mandatory in most centers to verify correct placement of the electrode array intra- or postoperatively, in particular, assessment of the insertion depth and the number of electrodes inserted. ${ }^{1,2}$ Radiography and fluoroscopy, typically using a transorbital or modified Stenvers view, were initially applied to cochlear implantation, ${ }^{3,4}$ but their major limitations were poor image resolution of the intracochlear structures and the lack of $3 \mathrm{D}$ views. Consequently, some cases of misplacement of the array into the semicircular canal or vestibule could not be distinguished intraoperatively. ${ }^{1,5,6}$ Thus, in many medical centers, HRCT, which provides better resolution and presents sagittal, axial, and coronal views, became the routine imaging procedure after cochlear implantation and before discharge. Nevertheless, the HRCT platform is fixed, and this imaging cannot be performed in the operating room like radiography and fluoroscopy. 
Table 1: Population characteristics ( $N=51$ patients)

\begin{tabular}{ll}
\hline \multicolumn{1}{c}{ Demographics } \\
\hline Age (mean \pm SEM) (range) (yr) & $53 \pm 7.1(20-87)$ \\
Sex (M/F) & $24: 27$ \\
Anatomy & \\
$\quad$ Normal & 64 ears \\
$\quad$ Major aplasia & 1 ear \\
Implanted side & \\
$\quad$ Left & 18 patients \\
$\quad$ Right & 19 patients \\
$\quad$ Bilateral & 14 patients \\
\hline
\end{tabular}

Note:-SEM indicates standard error of the mean.

\begin{tabular}{|c|c|c|c|}
\hline Devices & $\begin{array}{c}\text { Proprietary } \\
\text { Name }\end{array}$ & O-arm & HRCT \\
\hline Advanced Bionics (16 electrodes) & $\begin{array}{l}\text { Helix IJ } \\
\text { Mid-Scala }\end{array}$ & $\begin{array}{l}2 \\
3\end{array}$ & \\
\hline \multicolumn{4}{|l|}{ Cochlear (22 electrodes) } \\
\hline Perimodiolar & $\begin{array}{l}\mathrm{Cl} 24, \mathrm{Cl} 512 \\
\mathrm{Cl} 532\end{array}$ & $\begin{array}{r}12 \\
1\end{array}$ & 2 \\
\hline Straight & $\mathrm{Cl} 422, \mathrm{Cl} 522$ & 31 & 9 \\
\hline MED-EL (12 electrodes) & Flex 28 & 13 & 3 \\
\hline \multirow[t]{2}{*}{ Oticon (20 electrodes) } & Evo & 2 & \\
\hline & Standard & 1 & \\
\hline
\end{tabular}

Conebeam CT (CBCT), which was primarily developed for dental and maxillofacial imaging, is now used in cochlear implantation. ${ }^{7,8}$ In contrast to conventional spiral HRCT, which uses a narrow fan-shaped beam requiring multiple rotations around the patient to create a volume of data, CBCT only requires a single rotation of a cone-shaped beam that includes the whole FOV. The $\mathrm{x}$-ray source and the flat panel detector rotate around a fixed point in the center of the ROI. CBCT can provide higher spatial resolution and dynamic range than HRCT. Other advantages of CBCT include less intense metallic artifacts and lower radiation exposure than conventional multislice HRCT. ${ }^{9}$ During the past 10 years, CBCT has been developed as an alternative to HRCT in temporal bone imaging. ${ }^{10-13}$ Several studies have shown high sensitivity and specificity of nonmobile CBCT in the assessment of the scalar position of the electrode array in temporal bone specimens from cadavers. ${ }^{14-17}$ Furthermore, CBCT can be a mobile platform that can be used in the operating room. The purpose of this study was to assess the feasibility, reliability, and utility of mobile CBCT in the assessment of positioning of an electrode array in the operating room, immediately after cochlear implantation.

\section{MATERIALS AND METHODS}

All participants provided written informed consent allowing retrospective analysis of their data (CNIL No. 2040854).

\section{Patients}

A retrospective review was conducted on 51 patients (65 ears) who underwent cochlear implantation in a French tertiary medical center between July 2013 and March 2017 (Tables 1 and 2). An intraoperative radiologic evaluation (O-arm imaging system; Medtronic, Minneapolis, Minnesota) was performed after cochlear implantation and before the patients awoke from the anesthesia. Their medical records, including type of implant, surgical details, and radiologic images, were collected.

\section{Surgical Procedures}

The operation was performed by the same senior otologist. Cochlear implantation was performed in all cases using a minimally invasive protocol, ${ }^{18}$ with 4 brands of implant devices (Advanced Bionics, Valencia, California; Cochlear, Lane Cove, Australia; MED-EL, Innsbruck, Austria; and Oticon Medical, Vallauris, France).

\section{Radiologic Examinations and Analysis}

In 14 patients who had implantation on their second side, the electrode position of the first side was assessed on preoperative HRCT images (0.6-mm thickness), performed in the neuroradiologic center, using a Discovery CT 750 HD scanner (GE Healthcare, Milwaukee, Wisconsin). This assessment allowed a comparison of the imaging between HRCT and CBCT for the same implant, without an additional radiologic examination. The mean CT dose index of HRCT for these 14 patients was $91 \pm 10.4 \mathrm{mGy}$, and the dose-length product was $605 \pm 57.2 \mathrm{mGy} \cdot \mathrm{cm}^{2}$.

CBCT was performed immediately after closure of the incision using the $\mathrm{O}$-arm. The tube voltage was $120 \mathrm{kV}$, with a $12-\mathrm{mA}$ charge at the terminals. This intraoperative imaging platform provides $2 \mathrm{D}$ fluoroscopic imaging and a $360^{\circ}$ scan resulting in $3 \mathrm{D}$ multiplanar views. Fluoroscopy must be performed before the $3 \mathrm{D}$ acquisitions to verify the optimum positioning of the targeted ear in the gantry. The $3 \mathrm{D}$ imaging volume was cylindric $(15-\mathrm{cm}$ height $\times 20$-cm diameter; $512 \times 512 \times 192$ resolution), which was large enough to simultaneously detect both ears in 1 scan. After each scan, the 3D-MPR was automatically generated and 3 windows with planar images (coronal, sagittal, and axial) were immediately shown with free 3D rotation (Fig 1A). This process provided a slice thickness of $0.83 \mathrm{~mm}$ in the axial plane and 0.415 $\mathrm{mm}$ in the coronal and sagittal planes. One $360^{\circ}$ rotation of the $\mathrm{x}$-ray tube took 13 seconds. The CT dose index in the 51 patients was $12 \pm 2.6 \mathrm{mGy}$, and the dose-length product was $200 \pm 53.4$ $\mathrm{mGy} \cdot \mathrm{cm}^{2}$.

The patients underwent the operation on a radiolucent carbon fiber surgical table in a dedicated operating room with $\mathrm{x}$-ray protection. The installation and scanning with the $\mathrm{O}$-arm were performed by the surgeon. The duration from the entrance of CBCT into the operating room to the completion of scanning was timed. The CBCT images were assessed by the surgeon immediately after scanning to eliminate a misplacement of the electrode array into the vestibule or semicircular canals or a foldover of the intracochlear array.

The radiologic images were later analyzed by 2 specialists experienced in cochlear implant imaging. The depth angle and the length of insertion, the number of extracochlear electrodes, and the scalar position of the array at $180^{\circ}$ and $360^{\circ}$ depth were assessed using OsiriX Imaging Software (http:// www.osirix-viewer. com) as previously described. ${ }^{15,16}$ Briefly, the reconstruction plane for the evaluation of the electrode position was the midmodiolar plane obtained with the curved multiplanar reconstruction (3D Curved MPR Viewer in OsiriX). This plane was defined as a 3D Bézier path along the electrode array. Once the path was defined by the selection of all the single electrodes, the array was straightened and visible in the Curved MPR Viewer window. Then, the electrode array can be visualized in a dynamic series of 


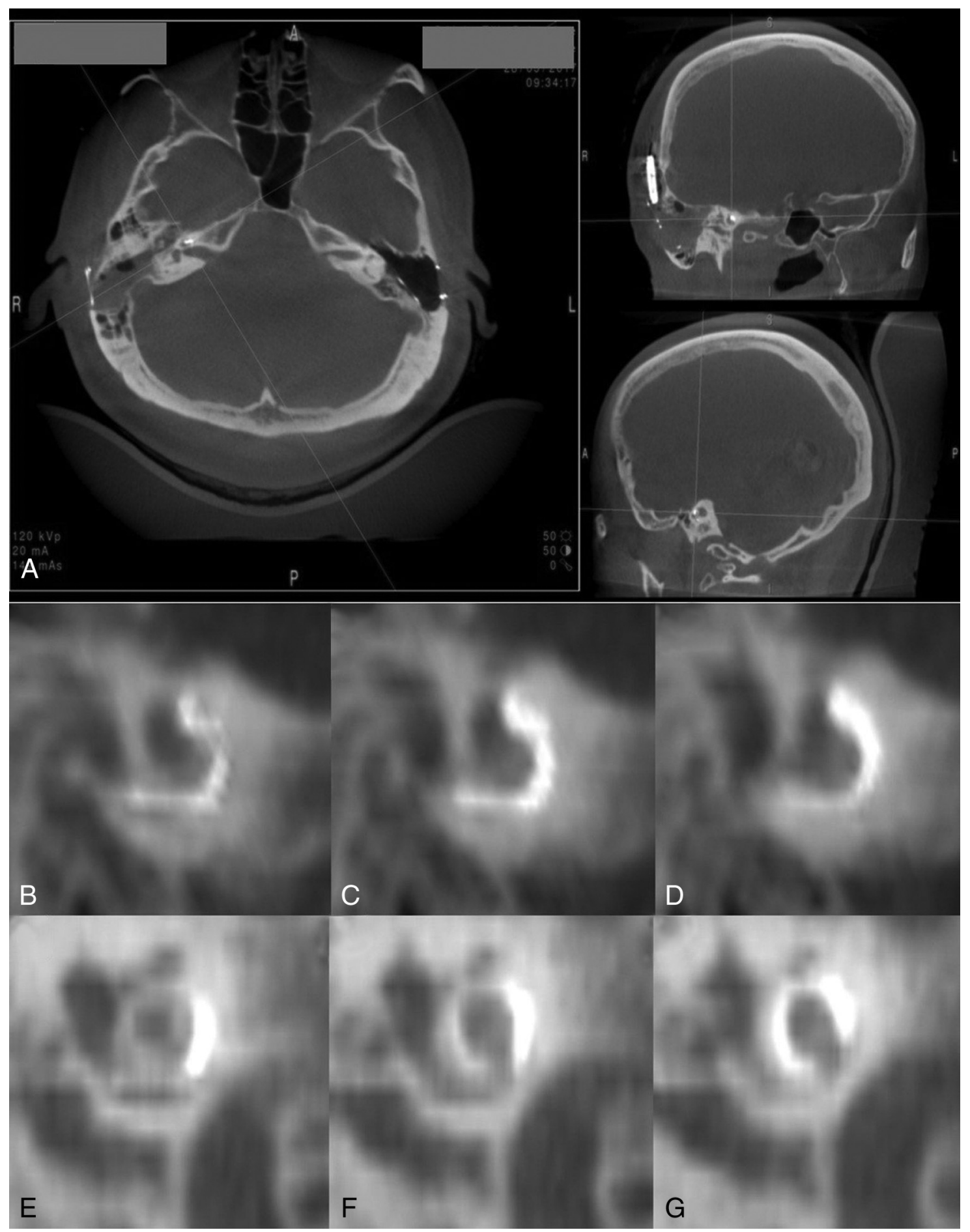

FIG 1. Output interface of the O-arm workstation and the case with foldover of the electrode array. The O-arm automatically shows the axial, sagittal, and coronal views on its screen after scanning and provides free 3D rotation $(A)$. A foldover of the $\mathrm{Cl} 532$ electrode array was observed on the original and consecutive sagittal views $(B-D)$. After a Cochlear $\mathrm{Cl} 522$ was re-implanted, the electrode array was verified in the correct position ( $E-G)$.

the midmodiolar section of the cochlea, and the raters estimated the localization, scala tympani, scala vestibuli, or intermediate position on the basis of the theoretic positions of the scala for electrodes positioned at $180^{\circ}$ and $360^{\circ}$. Assessment was performed independently and was timed. In cases in which there was a discrepancy in the number of extracochlear electrodes or in the scalar position between independent analyses, a coassessment was then performed by both raters to obtain a result with which they both agreed.

\section{Statistical Analysis}

Data are presented as mean \pm standard error of the mean. Interrater reliability was calculated using the intraclass correlation coefficient (ICC) for the quantitative variables insertion depth angle 
Table 3: Insertion depth angle and length of insertion of the electrode array-results from 2 raters using O-arm data ${ }^{a}$

\begin{tabular}{cccc}
\hline Implant & Rater & Depth Angle $\left(^{\circ}\right)$ & Length $(\mathrm{mm})$ \\
\hline Advanced Bionics & $\mathrm{A}$ & $384 \pm 28.8$ & $19.5 \pm 1.02$ \\
$(n=5)$ & $\mathrm{B}$ & $389 \pm 27.7$ & $19.5 \pm 0.96$ \\
Cochlear (perimodiolar) & $\mathrm{A}$ & $357 \pm 10.1$ & $18.8 \pm 0.71$ \\
$(n=12)$ & $\mathrm{B}$ & $360 \pm 9.5$ & $18.6 \pm 0.79$ \\
Cochlear (straight) & $\mathrm{A}$ & $425 \pm 12.9$ & $22.1 \pm 0.47$ \\
$(n=31)$ & $\mathrm{B}$ & $427 \pm 13.4$ & $22.3 \pm 0.47$ \\
MED-EL $(n=13)$ & $\mathrm{A}$ & $500 \pm 30.0$ & $24.1 \pm 0.90$ \\
& $\mathrm{~B}$ & $502 \pm 30.0$ & $24.4 \pm 0.93$ \\
Oticon $(n=3)$ & $\mathrm{A}$ & $370 \pm 13.2$ & $23.4 \pm 0.30$ \\
& $\mathrm{~B}$ & $366 \pm 21.7$ & $23.4 \pm 0.28$ \\
\hline
\end{tabular}

${ }^{a}$ Values are mean \pm standard error of the mean.

and insertion length or the Cohen $\kappa$ for the categoric variables electrode number and scalar position. The reliability of the electrode number with the total number of cases was calculated with the weighted data based on the electrode number of the implant device. Paired $t$ tests or Fisher exact tests were applied for comparison of variables. The criterion for statistical significance was set at $P<.05,2$-tailed. $\mathrm{R}$ statistical and computing software (http://www.r-project.org) was used.

\section{RESULTS}

\section{Analysis of Intraoperative Electrode Positioning Using the O-Arm}

The mean duration of installation and scanning was $5.4 \pm 1.2$ minutes. In this series, misplacement into the vestibule or semicircular canals was eliminated intraoperatively. In 1 case with major aplasia of the ear, the difficulty of implantation was increased by malformation of the middle ear, but the intraoperative images confirmed the correct position of the array. In another case in which a novel design of the array (CI 532; Coclear, Lane Cove, Australia) was implanted, a foldover of the inserted array was observed (Fig $1 B-D$ ). This patient was re-implanted with a CI 522 (Cochlear), and the new electrode array was inserted correctly with an insertion depth angle of $399^{\circ}$ and insertion length of 22.4 $\mathrm{mm}$ (Fig $1 E-G$ ). The case of foldover was excluded from the OsiriX analysis.

\section{Assessment of Electrode Positioning}

Independent assessments were performed by 2 raters for 64 ears with $\mathrm{O}$-arm data, using the MPR viewer of OsiriX. The mean time for analysis was $3.1 \pm 1.1$ minutes for one rater and $3.7 \pm 0.4$ minutes for the other. There was an excellent agreement between raters for the depth angle of insertion (ICC $=0.96, P<.001$ ) and insertion length (ICC $=0.93, P=.04$ ), with a non-statistically significant difference between raters of $8^{\circ} \pm 0.8^{\circ}$ for insertion depth angle and $0.6 \pm 0.1 \mathrm{~mm}$ for insertion length (Table 3 ).

Because the intracochlear electrodes were not clearly shown on O-arm images (Fig 2G, $-H$ ), apart from those of the MED-EL implant, which has only 12 electrodes (Fig $2 E,-F$ ), the extracochlear electrodes that were more clearly identified were counted. Their numbers were assessed identically between the 2 raters in 50 ears $(78 \%$, Cohen $\kappa=0.53, P<.001)$, and the identical rates among the different types of arrays did not show a statistically significant difference (Table 4). Regarding the scalar position of the electrodes, initial assessment was the same between raters in only $34 / 64$ ears $(53 \%)$ at $180^{\circ}$ and $20 / 46$ ears $(43 \%)$ at $360^{\circ}$, with

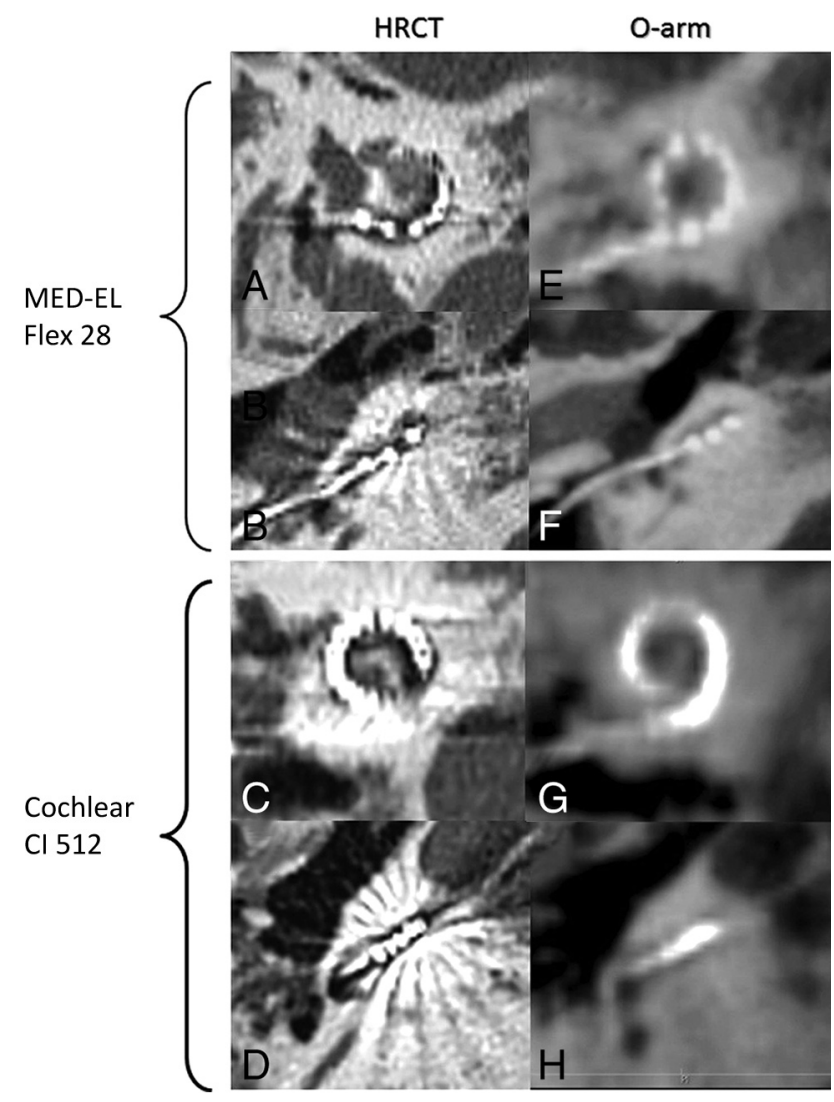

FIG 2. Examples of radiologic images of HRCT and the O-arm for 2 types of cochlear implants. MED-EL Flex $28(A, B, E, F)$ and Cochlear $C l$ $512(C, D, G, H)$ electrode arrays were observed with both HRCT $(A-D)$ and the $O$-arm $(E-H)$, and with sagittal $(A, C, E, G)$ and axial $(B, D, F, H)$ views.

no significant consistency between the evaluations of the 2 raters (Cohen $\kappa=0.16, P=.10$ at $180^{\circ}$; and Cohen $\kappa=0.14, P=.05$ at $\left.360^{\circ}\right)$. After coassessment by the 2 raters, no significant difference was found for the various types of arrays, for the rate of extracochlear electrodes, or for the scalar position (Table 5).

\section{Concordance of the Electrode Assessment between HRCT and the O-Arm}

When comparing coassessment results obtained by HRCT and $\mathrm{O}$-arm in the 14 ears of patients who had implantation on their second side, we found an excellent agreement for the insertion depth angle (ICC $=0.97, P<.001$ ) and the insertion length (ICC $=0.98, P<.001)$, with a non-statistically significant difference of $11^{\circ} \pm 2.2^{\circ}$ for the insertion depth angle and of $0.4 \pm 0.1$ $\mathrm{mm}$ for the insertion length. The number of extracochlear electrodes was identical in 13/14 ears (93\%) and showed good agreement (Cohen $\kappa=0.63, P=.01$ ). Analysis of the scalar position of the array still showed a moderate agreement at $180^{\circ}(79 \%$, Cohen $\kappa=0.59, P=.02)$ and a nonsignificant agreement at $360^{\circ}(75 \%$, Cohen $\kappa=0.44, P=.06$ ) (Table 6).

\section{DISCUSSION}

Misplacement of electrode arrays into the vestibule or semicircular canals or foldover of inserted arrays has been reported in about $0.2 \%-1 \%$ of patients $\mathrm{s}^{4,19-21}$ and needed to be surgically corrected. Electrophysiologic measurements, such as impedance or neural 
Table 4: Extracochlear electrode number and scalar position—difference in the results of 2 raters using 0 -arm data

\begin{tabular}{|c|c|c|c|c|c|c|c|}
\hline & \multicolumn{3}{|c|}{$\begin{array}{l}\text { Electrode No. Counting } \\
\text { Rater A vs B } \\
\end{array}$} & \multicolumn{2}{|c|}{$\begin{array}{c}\text { Scalar Position at } 180^{\circ} \\
\text { Rater A vs B } \\
\end{array}$} & \multicolumn{2}{|c|}{$\begin{array}{c}\text { Scalar Position at } 360^{\circ a} \\
\text { Rater A vs B } \\
\end{array}$} \\
\hline & Same & \pm 1 & \pm 2 & Same & Different & Same & Different \\
\hline Advanced Bionics $(n=5)$ & $3(60 \%)$ & $2(40 \%)$ & & $4(80 \%)$ & $1(20 \%)$ & $2 / 3(67 \%)$ & $1 / 3(33 \%)$ \\
\hline Cochlear (perimodiolar) $(n=12)$ & $9(75 \%)$ & $2(17 \%)$ & $1(8 \%)$ & $6(50 \%)$ & $6(50 \%)$ & $5 / 9(55 \%)$ & $4 / 9(45 \%)$ \\
\hline Cochlear (straight) $(n=31)$ & $25(80 \%)$ & $3(10 \%)$ & $3(10 \%)$ & $14(45 \%)$ & $17(55 \%)$ & $6 / 21(29 \%)$ & $15 / 21(71 \%)$ \\
\hline $\operatorname{MED}-\operatorname{EL}(n=13)$ & $11(85 \%)$ & $2(15 \%)$ & & $8(62 \%)$ & $5(38 \%)$ & 6/11 (55\%) & $5 / 11(45 \%)$ \\
\hline Oticon $(n=3)$ & $2(67 \%)$ & & $1(33 \%)$ & $2(67 \%)$ & $1(33 \%)$ & $1 / 2(50 \%)$ & $1 / 2(50 \%)$ \\
\hline Total $(n=64)$ & $50^{\mathrm{b}}(78 \%)$ & $9(14 \%)$ & $5(8 \%)$ & $34^{c}(53 \%)$ & $30(47 \%)$ & $20 / 46^{c}(43 \%)$ & $26 / 46(57 \%)$ \\
\hline
\end{tabular}

a Some electrode arrays did not pass $360^{\circ}$ depth, so the number of measurable cases at $360^{\circ}$ was less than at $180^{\circ}$. The number of cases is indicated.

${ }^{\mathrm{b}}$ Cohen $\kappa=0.53(P<.001)$. Among the different array types, the raters' concordance showed no significant difference.

${ }^{c}$ Cohen $\kappa<0.2$ (not significant).

Table 5: Extracochlear electrode number and scalar position—final results after coassessment using O-arm data

\begin{tabular}{|c|c|c|c|c|c|c|c|c|c|c|c|}
\hline & \multicolumn{5}{|c|}{ No. of Extracochlear Electrodes } & \multicolumn{3}{|c|}{ Scalar Position at $180^{\circ}$} & \multicolumn{3}{|c|}{ Scalar Position at $360^{\circ a}$} \\
\hline & 0 & 1 & 2 & 3 & 4 & ST & Int & sv & ST & Int & sv \\
\hline Advanced Bio & $2(40 \%)$ & $1(20 \%)$ & $2(40 \%)$ & & & $3(60 \%)$ & $1(20 \%)$ & $1(20 \%)$ & $2 / 3(67 \%)$ & & $1 / 3(33 \%)$ \\
\hline Cochlear (perimodiolar) $(n=12)$ & $6(50 \%)$ & $3(25 \%)$ & $2(17 \%)$ & & $1(8 \%)$ & $6(50 \%)$ & $5(42 \%)$ & $1(8 \%)$ & $3 / 9(33 \%)$ & $5 / 9(56 \%)$ & $1 / 9(11 \%)$ \\
\hline Cochlear (straight) $(n=31)$ & $26(84 \%)$ & $1(3 \%)$ & $1(3 \%)$ & $2(6 \%)$ & $1(3 \%)$ & $16(52 \%)$ & $12(38 \%)$ & $3(10 \%)$ & $5 / 21(24 \%)$ & $13 / 21(62 \%)$ & $3 / 21(14 \%)$ \\
\hline $\operatorname{MED}-E L(n=13)$ & $10(77 \%)$ & $1(8 \%)$ & $2(15 \%)$ & & & $9(69 \%)$ & $4(31 \%)$ & & $7 / 11(64 \%)$ & $4 / 11(36 \%)$ & \\
\hline Oticon $(n=3)$ & $1(33 \%)$ & $1(33 \%)$ & $1(33 \%)$ & & & $1(33 \%)$ & $2(67 \%)$ & & $1 / 2(50 \%)$ & $1 / 2(50 \%)$ & \\
\hline Total $(n=64)$ & $45(70 \%)$ & $7(11 \%)$ & $8(13 \%)$ & $2(3 \%)$ & $2(3 \%)$ & $35(55 \%)$ & $24(38 \%)$ & $5(7 \%)$ & $18 / 46(39 \%)$ & $23 / 46(50 \%)$ & $5 / 46(11 \%)$ \\
\hline
\end{tabular}

Note:-ST indicates scala tympani; Int, intermediate position; SV: scala vestibuli.

a Some electrode arrays did not pass $360^{\circ}$ depth, so the number of measurable cases at $360^{\circ}$ was less than at $180^{\circ}$. The number of cases is indicated.

Table 6: Concordances of raters' coassessment between HRCT and O-arm-extracochlear electrode number and scalar position

\begin{tabular}{|c|c|c|c|c|c|c|}
\hline & \multicolumn{2}{|c|}{$\begin{array}{l}\text { No. of Extracochlear } \\
\text { Electrodes } \\
\text { HRCT vs O-Arm }\end{array}$} & \multicolumn{2}{|c|}{$\begin{array}{l}\text { Scalar Position at } 180^{\circ} \\
\text { HRCT vs O-Arm }\end{array}$} & \multicolumn{2}{|c|}{$\begin{array}{l}\text { Scalar Position at } 360^{\circ a} \\
\text { HRCT vs O-Arm }\end{array}$} \\
\hline & Same & \pm 1 & Same & Different & Same & Different \\
\hline Cochlear $(n=11)$ & $10(91 \%)$ & $1(9 \%)$ & $8(73 \%)$ & $3(27 \%)$ & $6 / 9(67 \%)$ & $3 / 9(33 \%)$ \\
\hline MED-EL $(n=3)$ & $3(100 \%)$ & & $3(100 \%)$ & & $3 / 3(100 \%)$ & \\
\hline Total $(n=14)$ & $13(93 \%)$ & $1(7 \%)$ & $11(79 \%)$ & $3(21 \%)$ & $9 / 12$ (75\%) & $3 / 12(25 \%)$ \\
\hline
\end{tabular}

${ }^{a}$ Some electrode arrays did not pass $360^{\circ}$ depth, so the number of measurable cases at $360^{\circ}$ was less than at $180^{\circ}$. The number of cases is indicated.

response telemetry, can be performed immediately after implantation to verify the normal function of the electrode array; however, some intraoperative electrophysiologic measurements have been reported to be normal or near-normal in cases of misplacement. $^{5,22,23}$ In the present study, 1 patient presented with a foldover of the array, but intraoperative electrophysiologic measurements did not indicate abnormalities, so imaging was the exclusive method used to diagnose this misplacement. In the absence of postoperative imaging or in the case of misdiagnosis by fluoroscopy, a misplacement outside the cochlea might only be suspected at the first mapping, generally about 2-4 weeks after implantation, and then confirmed by HRCT. These patients have lost the optimum timing for revision surgery because the delay between the first surgery and revision increases the importance of tissue repair and fibrosis around the round window or cochleostomy site and thus may provoke more bleeding or damage in the inner ear. ${ }^{20,24,25}$ If HRCT or CBCT is performed as routine postoperative imaging and a misplacement is reported, an additional anesthetic procedure is required for the revision surgery. Furthermore, for recipients who are children, postoperative HRCT is not a routine imaging procedure in many centers and sometimes is a complex procedure requiring sedation and special care. Therefore, intraoperative imaging is very useful and could be indicated at least for individuals who present a risk for a challenging operation because of inner ear malformations and pathologic narrow- ing or obstruction of the cochlear scalae in the case of meningitis, trauma, or otosclerosis. ${ }^{21}$

CBCT by the $\mathrm{O}$-arm is designed for intraoperative use, with a radiolucent carbon fiber surgical table in a dedicated operating room with $\mathrm{x}$-ray protection and can be performed before closing the incision using a sterile tube drape. Even though this version of the $\mathrm{O}$-arm software could not realize a maximum intensity projection on its platform, which can rebuild the entire electrode array, a function of free 3D rotation was provided and was very helpful for careful assessment of array positioning. Because of the easy manipulation with the $\mathrm{O}$-arm, the installation, scanning, and assessment of the electrode array can be performed by the surgeon when the protocol is established. In this study, the performance of the $\mathrm{O}$-arm in the operating room was successfully and quickly realized in all cases. In addition, the lower radiation dose compared with HRCT makes it a safer imaging technique. ${ }^{26}$

With advanced software for DICOM such as OsiriX, which has been approved as a reliable and rapid method for assessing radiologic imaging, ${ }^{16}$ a more detailed positioning assessment of the electrode array can be realized in the operating room and can give timely feedback to the surgeon. In this series, the insertion depth angle and the length of insertion of the electrode array were assessed promptly ( $\sim 3-4$ minutes) and showed excellent agreement between the raters' independent assessments. These results also showed excellent agreement with those based on HRCT im- 
ages, which is the most common imaging procedure and is considered the criterion standard postoperative protocol for the evaluation of electrode arrays in adults. For electrode counting, there was also good agreement between raters, even though it was difficult to clearly distinguish the electrodes near the round window or cochleostomy on $\mathrm{O}$-arm images, especially for arrays with a high number of electrodes (Fig 2); however, the accuracy of electrode counting by the $\mathrm{O}$-arm was still acceptable compared with HRCT. Consequently, O-arm imaging can be considered a reliable tool for assessing the electrode array position in the cochlea in current practice.

Besides correct placement in the cochlea, translocation into the scala vestibuli is increasingly being studied because it might be associated with poor speech performance. ${ }^{27}$ In this series, the scalar positioning was difficult to evaluate on $\mathrm{O}$-arm images and a poor interrater agreement was found, whereas other studies have reported more accurate identification of the scalar position. ${ }^{16,17,28,29}$ This difference might be explained by the technologic differences between mobile and fixed CBCT equipment, such as the i-CAT 3D Imaging System (Imaging Sciences International, Hatfield, Pennsylvania), ILUMA Ultra Cone Beam CT Scanner (IMTEC Imaging, Ardmore, Oklahoma), and NewTom 5G or NewTom VGI CBCT scanner (NewTom, Verona, Italy). ${ }^{13,14,16}$ Furthermore, analysis by a senior neuroradiologist or with coregistration of preoperative and postoperative images could give a more accurate assessment of the scalar position, ${ }^{10,28,30-33}$ but this takes a long time and is not feasible for current intraoperative use. Finally, up to now, lack of diagnosis of a translocation is not of primary importance because it is not an indication for re-insertion of the array.

\section{CONCLUSIONS}

The $\mathrm{O}$-arm is an imaging platform with mobility, rapid installation, quick scanning, intraoperative use, and low radiation dose. It provides reliable image quality for eliminating misplacement of electrode arrays into the vestibule or semicircular canals or foldover of the inserted array; for measuring the insertion depth angle and length of insertion; and for counting the number of electrodes inserted, which makes it a practical radiologic technique for assessment of electrode array positioning in the operating room. This is particularly useful for patients in a 1-day operation and in the case of a challenging operation. This device could potentially be combined with navigation or robotic systems. It could also be shared by different disciplines, such as neurosurgery and orthopedics; this feature makes it a valuable piece of equipment in the operating room.

\section{ACKNOWLEDGMENTS}

We thank Haoyue Tan for her assistance with statistical analysis and Colin Woodham for language editing.

Disclosures: Olivier Sterkers—UNRELATED: Consultancy: Medtronic, Comments: monitoring of the facial nerve.

\section{REFERENCES}

1. Gnagi SH, Baker TR, Pollei TR, et al. Analysis of intraoperative radiographic electrode placement during cochlear implantation. Otol Neurotol 2015;36:1045-47 CrossRef Medline
2. Xu J, Xu SA, Cohen LT, et al. Cochlear view: postoperative radiography for cochlear implantation. Am J Otol 2000;21:49-56 Medline

3. Viccaro M, Covelli E, De Seta E, et al. The importance of intra-operative imaging during cochlear implant surgery. Cochlear Implants Int 2009;10:198-202 CrossRef Medline

4. Ying YL, Lin JW, Oghalai JS, et al. Cochlear implant electrode misplacement: incidence, evaluation, and management. Laryngoscope 2013;123:757-66 CrossRef Medline

5. Sun JQ, Sun JW, Hou XY, et al. Electrode array misplacement into the superior semicircular canal: as a rare complication of cochlear implantation. Int J Pediatr Otorhinolaryngol 2014;78:1537-40 CrossRef Medline

6. Hassan AM, Patel R, Redleaf M. Intra-operative skull X-ray for misdirection of the cochlear implant array into the vestibular labyrinth. J Laryngol Otol 2015;129:923-27 CrossRef Medline

7. Richter B, Aschendorff A, Lohnstein P, et al. The Nucleus Contour electrode array: a radiological and histological study. Laryngoscope 2001;111:508-14 CrossRef Medline

8. Husstedt HW, Aschendorff A, Richter B, et al. Nondestructive threedimensional analysis of electrode to modiolus proximity. Otol $\mathrm{Neu}$ rotol 2002;23:49-52 CrossRef Medline

9. Arweiler-Harbeck D, Mönninghoff C, Greve J, et al. Imaging of electrode position after cochlear implantation with flat panel CT. ISRN Otolaryngol 2012;2012:728205 CrossRef Medline

10. Aschendorff A, Kubalek R, Turowski B, et al. Quality control after cochlear implant surgery by means of rotational tomography. Otol Neurotol 2005;26:34-37 CrossRef Medline

11. Miracle AC, Mukherji SK. Conebeam CT of the head and neck, part 2: clinical applications. AJNR Am J Neuroradiol 2009;30:1285-92 CrossRef Medline

12. Dahmani-Causse M, Marx M, Deguine O, et al. Morphologic examination of the temporal bone by conebeam computed tomography: comparison with multislice helical computed tomography. Eur Ann Otorhinolaryngol Head Neck Dis 2011;128:230-35 CrossRef Medline

13. Stutzki M, Jahns E, Mandapathil MM, et al. Indications of conebeam CT in head and neck imaging. Acta Otolaryngol 2015;135:1337-43 CrossRef Medline

14. Marx M, Risi F, Escudé B, et al. Reliability of conebeam computed tomography in scalar localization of the electrode array: a radio histological study. Eur Arch Otorhinolaryngol 2014;271:673-79 CrossRef Medline

15. Kurzweg T, Dalchow CV, Bremke M, et al. The value of digital volume tomography in assessing the position of cochlear implant arrays in temporal bone specimens. Ear Hear 2010;31:413-19 CrossRef Medline

16. De Seta D, Mancini P, Russo FY, et al. 3D curved multiplanar cone beam CT reconstruction for intracochlear position assessment of straight electrodes array: a temporal bone and clinical study. Acta Otorhinolaryngol Ital 2016;36:499-505 CrossRef Medline

17. Mosnier I, Célérier C, Bensimon JL, et al. Conebeam computed tomography and histological evaluations of a straight electrode array positioning in temporal bones. Acta Otolaryngol 2017;137:229-34 CrossRef Medline

18. Nguyen Y, Mosnier I, Borel S, et al. Evolution of electrode array diameter for hearing preservation in cochlear implantation. Acta Otolaryngol 2013;133:116-22 CrossRef Medline

19. Loundon N, Blanchard M, Roger G, et al. Medical and surgical complications in pediatric cochlear implantation. Arch Otolaryngol Head Neck Surg 2010;136:12-15 CrossRef Medline

20. Lee J, Eddington DK, Nadol JB. The histopathology of revision cochlear implantation. Audiol Neurootol 2011;16:336-46 CrossRef Medline

21. Jiang Y, Gu P, Li B, et al. Analysis and management of complications in a cohort of 1,065 minimally invasive cochlear implantations. Otol Neurotol 2017;38:347-51 CrossRef Medline

22. Pijl S, Westerberg BD, Gustin C, et al. Objective findings with malpositioning of a nucleus $24 \mathrm{RE}(\mathrm{CA})$ cochlear implant. J Am Acad Audiol 2008;19:435-42 CrossRef Medline 
23. Cosetti MK, Shapiro WH, Green JE, et al. Intraoperative neural response telemetry as a predictor of performance. Otol Neurotol 2010; 31:1095-99 CrossRef Medline

24. Tien HC, Linthicum FH. Histopathological changes in the vestibule after cochlear implantation. Otolaryngol Head Neck Surg 2002;127: 260-64 CrossRef Medline

25. Bas E, Goncalves S, Adams M, et al. Spiral ganglion cells and macrophages initiate neuro-inflammation and scarring following cochlear implantation. Front Cell Neurosci 2015;9:303 CrossRef Medline

26. Schulze R. Radiation protection vs research interests. Dentomaxillofac Radiol 2013;42:20120348 CrossRef Medline

27. Holden LK, Finley CC, Firszt JB, et al. Factors affecting open-set word recognition in adults with cochlear implants. Ear Hear 2013; 34:342-60 CrossRef Medline

28. Boyer E, Karkas A, Attye A, et al. Scalar localization by cone beam computed tomography of cochlear implant carriers: a comparative study between straight and periomodiolar precurved electrode arrays. Otol Neurotol 2015;36:422-29 CrossRef Medline

29. Theunisse HJ, Joemai RMS, Maal TJ, et al. Cone-beam CT versus multi-slice CT systems for postoperative imaging of cochlear implantation: a phantom study on image quality and radiation exposure using human temporal bones. Otol Neurotol 2015;36:592-99 CrossRef Medline

30. Skinner MW, Holden TA, Whiting BR, et al. In vivo estimates of the position of advanced bionics electrode arrays in the human cochlea. Ann Otol Rhinol Laryngol Suppl 2007;197:2-24 Medline

31. Schuman TA, Noble JH, Wright CG, et al. Anatomic verification of a novel method for precise intrascalar localization of cochlear implant electrodes in adult temporal bones using clinically available computed tomography. Laryngoscope 2010;120:2277-83 CrossRef Medline

32. Helbig S, Mack M, Schell B, et al. Scalar localization by computed tomography of cochlear implant electrode carriers designed for deep insertion. Otol Neurotol 2012;33:745-50 CrossRef Medline

33. Lane JI, Witte RJ, Driscoll CLW, et al. Scalar localization of the electrode array after cochlear implantation: clinical experience using 64-slice multidetector computed tomography. Otol Neurotol 2007; 28:658-62 Medline 